Copyright (C) 2008 IEEE. Reprinted from IEEE Transactions on Industry Applications, 2006; 42 (6):1478-1486

This material is posted here with permission of the IEEE. Such permission of the IEEE does not in any way imply IEEE endorsement of any of the University of Adelaide's products or services. Internal or personal use of this material is permitted. However, permission to reprint/republish this material for advertising or promotional purposes or for creating new collective works for resale or redistribution must be obtained from the IEEE by writing to pubs-permissions@ieee.org.

By choosing to view this document, you agree to all provisions of the copyright laws protecting it. 


\title{
Iron Loss Reduction in an Interior PM Automotive Alternator
}

\author{
Vlatka Životić-Kukolj, Wen L. Soong, Member, IEEE, and Nesimi Ertugrul, Member, IEEE
}

\begin{abstract}
This paper examines the iron loss characteristics of a high-flux interior permanent-magnet machine. The machine was designed as a concept demonstrator for a $6-\mathrm{kW}$ automotive alternator and has a wide field-weakening range. Initial experimental results revealed a high iron loss during field-weakening operation. Finite-element analysis was used to investigate the cause of the high iron losses and to predict their magnitude as a function of speed. The effects of changes in the machine design were examined in order to reduce iron losses and hence improve the machine performance.
\end{abstract}

Index Terms-Alternator, field weakening, finite-element analysis (FEA), interior permanent-magnet (PM) machines, iron loss.

\section{INTRODUCTION}

\section{A. High-Power Alternator Specification}

The automotive industry is currently looking into the development of low-cost high-power alternators in order to satisfy the projected electrical power demands of next-generation vehicles. A proposed specification for a high-power belt-driven automotive alternator is a linearly increasing output power from 4 to $6 \mathrm{~kW}$ as the alternator's speed increases from idle (1.8 $\mathrm{kr} / \mathrm{min})$ to maximum operating speed (18 kr/min), assuming a $3: 1$ belt ratio [1]. This challenging $10: 1$ constant power speed range is achievable only when the machine works in the field-weakening regime. At high speeds, the alternator operates at high frequencies, which can make iron loss an issue.

\section{B. Concept Demonstrator and Machine Loss Measurements}

An interior permanent-magnet (PM) concept demonstrator for a $6-\mathrm{kW}$ automotive alternator was described in [2]. Fig. 1 shows the measured and calculated output power characteristics of the interior PM machine showing the potential to meet the

Paper IPCSD-06-056, presented at the 2005 Industry Applications Society Annual Meeting, Hong Kong, October 2-6, and approved for publication in the IEEE TRANSACTIONS ON INDUSTRY APPLICATIONS by the Electric Machines Committee of the IEEE Industry Applications Society. Manuscript submitted for review July 30, 2005 and released for publication July 10, 2006. This work was supported by Australian Research Council Discovery Grant DP0342874.

The authors are with the School of Electrical and Electronic Engineering, University of Adelaide, Adelaide, SA 5005, Australia (e-mail: vlatka@eleceng. adelaide.edu.au; wlsoong@eleceng.adelaide.edu.au; nesimi@eleceng.adelaide. edu.au).

Color versions of Figs. 5, 6, 8, 9, 13, and 16-19 are available online at http://ieeexplore.ieee.org.

Digital Object Identifier 10.1109/TIA.2006.882660

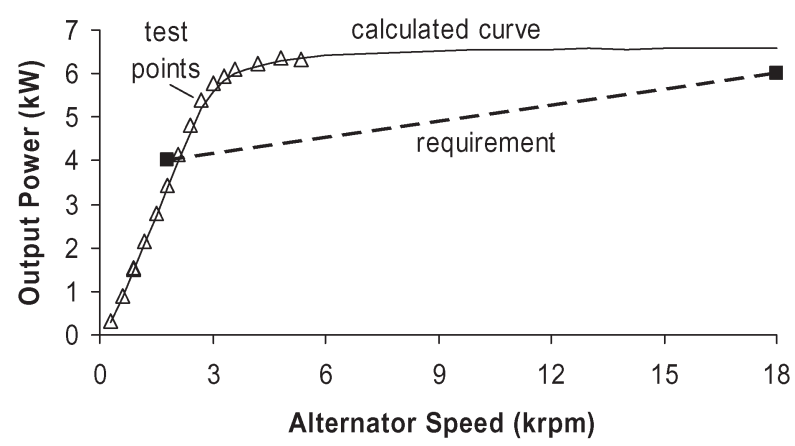

Fig. 1. Output power of the interior PM alternator. Measured results (triangles) and calculated performance based on the measured equivalent circuit parameters (solid line) at rated voltage. The high-power alternator specification is also shown [2].

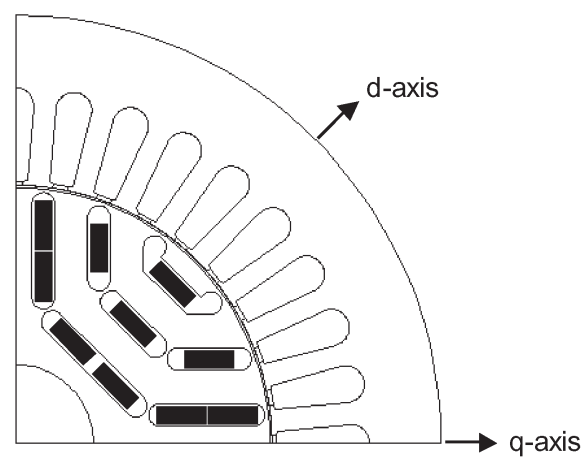

Fig. 2. Rotor and stator lamination cross section showing the location of the rotor magnets.

high-power alternator specification. The experimental results were restricted to $6 \mathrm{kr} / \mathrm{min}$ by dynamometer limitations.

The concept demonstrator is a high-flux interior PM machine which uses rare-earth magnets $(\mathrm{NdFeB})$. The machine is based on a commercial $415-\mathrm{V} 2.2-\mathrm{kW}$ four-pole induction motor stator and uses a custom designed rotor having three flux barriers per pole (see Fig. 2). The motor stack length is $95 \mathrm{~mm}$, the stator outer diameter is $153 \mathrm{~mm}$, the rotor diameter is $92 \mathrm{~mm}$, and the air gap is $0.39 \mathrm{~mm}$. The rotor lamination design uses a number of rounded bridges to mechanically retain the magnets at high speed.

Fig. 3 shows the machine's measured efficiency at rated output corresponding to the output power curve shown in Fig. 1. Below $2.5 \mathrm{kr} / \mathrm{min}$, the copper losses dominate and they are relatively constant, and thus as the output power increases with speed so does the efficiency. Above $2.5 \mathrm{kr} / \mathrm{min}$, the output 


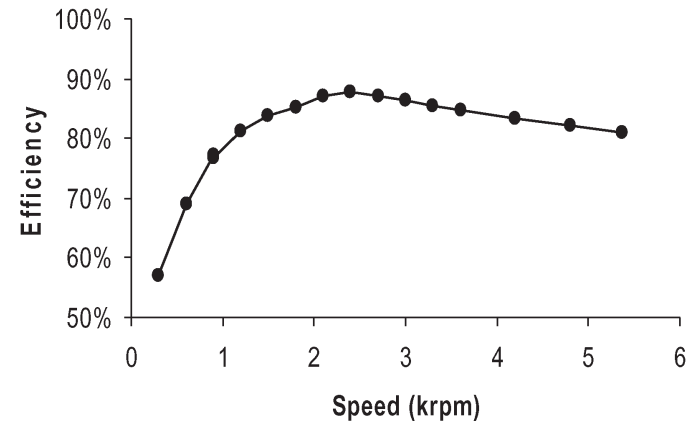

Fig. 3. Measured efficiency at rated output of the interior PM machine [2].

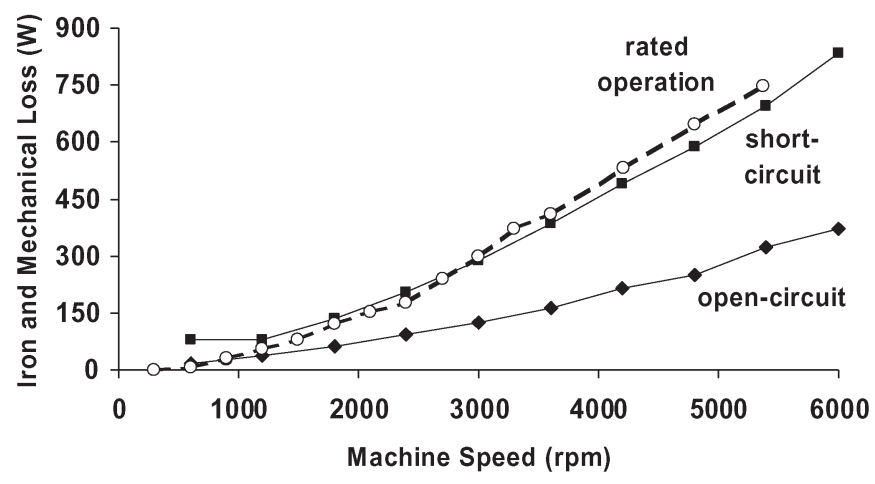

Fig. 4. Measured iron and mechanical losses as a function of speed under open-circuit, short-circuit, and rated output conditions.

power and copper loss are relatively constant and the drop in efficiency is due to increasing iron losses.

Experimental loss measurements were taken on the machine to examine the variation of iron losses with speed and operating conditions. Fig. 4 shows the measured iron and mechanical losses of the concept demonstrator machine as a function of speed under open-circuit, short-circuit, and rated output voltage conditions [3].

The concept demonstrator machine has a high inductance resulting in a short-circuit current which is equal to the rated current, which gives it a wide field-weakening range [2]. Particularly at higher speeds, the back electromotive force (EMF) is much greater than the output voltage and hence rated operation is close to the short-circuit condition. Thus, the iron losses under rated conditions is close to the iron losses in short-circuit operation.

This is opposite to conventional PM machines where the rated current is usually much smaller than the short-circuit current and where rated operation (and hence iron losses) are close to the open-circuit condition.

At high speeds under short-circuit conditions, ideally the stator and rotor flux should cancel one another, resulting in a nearly zero air-gap flux and low iron loss. In practice, Fig. 4 shows that the losses under short-circuit conditions are roughly twice that under open-circuit conditions.

\section{Literature Review of Iron Loss Under Field-Weakening Operation}

The cause of the high iron losses during field-weakening operation of interior PM motors has been examined using time- stepping finite-element analysis (FEA) by Tseng and Wee [4], Stumberger et al. [5]-[6], and Schiferl and Lipo [7]. They identified three main causes.

1) Harmonic air-gap flux components: Particularly, under low-flux field-weakening conditions, large harmonic airgap flux components were found which caused significant levels of stator core loss [6]. In one case, the core loss due to the high-harmonic components was six times greater than the core loss due to the fundamental component. The air-gap flux harmonics are associated with large zigzag flux components caused by the $d$-axis stator current saturating the rotor leakage flux paths [7].

2) Large rotational components of flux density: Particularly in the stator back iron [6].

3) Losses in the rotor iron near the air gap: Normally, the iron losses in the rotor are assumed to be small in synchronous machines, however the harmonic air-gap fluxes can cause significant rotor iron losses which can be up to $30 \%$ of the total iron loss [6].

They showed that the application of two-dimensional (2-D) finite-element methods can produce an accurate prediction of the stator core loss including the effects of nonsinusoidal flux density waveforms.

This previous research showed that due to the above reasons, for interior PM synchronous machines in low-flux operation, the presence of higher stator core harmonic fields should be expected. This is increasingly important at higher speeds [7].

\section{Paper Outline}

The contents of this paper are as follows. In Section II, 2-D FEA is used to predict the iron losses under field-weakening conditions and these are compared with the experimental measurements. In Section III, the effect of changes in the machine design is examined to gain an understanding of how it can be improved to reduce the iron losses. Finally, in Section IV, the experimental validation of the improvement from one of the design changes examined in Section III is described.

\section{Concept Demonstrator Iron Loss Analysis}

In this section, FEA is used to examine the flux distribution during open-circuit and field-weakening conditions of the concept demonstrator machine. Due to symmetry reasons, only a quarter of the machine has been analyzed. The Magsoft Flux2D package was used in the analysis ${ }^{1}$ and the model used 23000 elements.

It should be noted that the rare-earth magnets do not take up the entire area of the rotor slots (flux barriers) as shown in Fig. 2. The magnets were modeled by reducing the magnet remanent flux density by the ratio of the magnet area to the slot area. The magnet properties are as follows: sintered $\mathrm{NdFeB}$ blocks, remanent flux density $1.1 \mathrm{~T}$ and relative recoil permeability $\mu_{\mathrm{r}}=1.05$. A linear second quadrant demagnetization characteristic was assumed.

\footnotetext{
${ }^{1}$ http://www.magsoft-flux.com/Products/Flux/.
} 


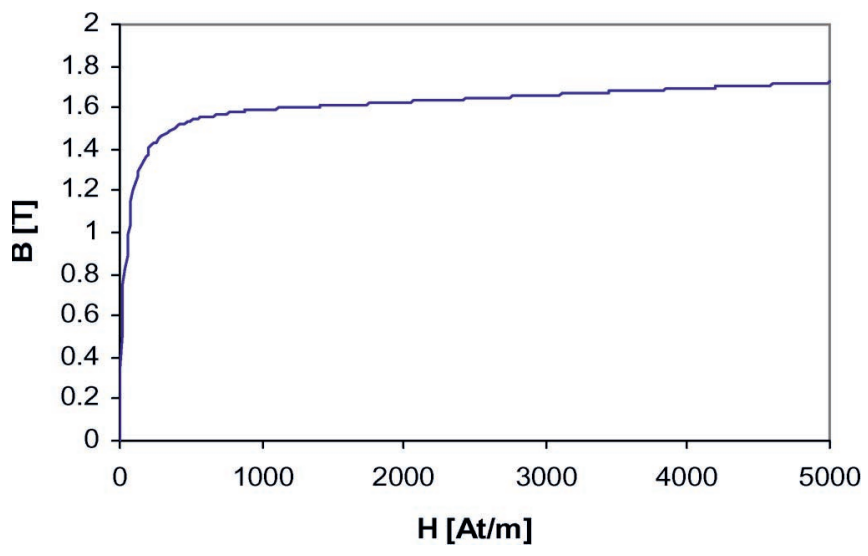

Fig. 5. B-H curve of Polycor $0.3 \%$ silicon iron laminations used in the rotor and stator FEA modeling.

The B-H curve of Polycor $0.3 \%$ silicon iron laminations has been used in all calculations (see Fig. 5).

\section{A. Calculated Spatial Air-Gap Flux Density}

Fig. 6 shows the calculated flux distribution and spatial air-gap radial flux density graphs for the concept demonstrator machine under three conditions, which from left to right are:

1) open circuit: rotor magnets only, no stator current, hence rotor flux only;

2) reluctance rotor: no rotor magnets, rated $d$-axis stator current, hence stator flux only; and

3) short circuit (field-weakening): rotor magnets and rated $d$-axis stator current opposing the magnet flux, includes both stator and rotor flux.

The open-circuit air-gap flux density graph [Fig. 6(a)] has a rectangular shape with a peak value of approximately $0.7 \mathrm{~T}$. The dips in the waveform correspond to the stator slotting. Note that reducing the width of the stator slot openings will reduce the depth of the dips. The fundamental component of the spatial air-gap flux waveform has a peak value of $0.66 \mathrm{~T}$.

The reluctance rotor $d$-axis air-gap flux density waveform [Fig. 6(b)] shows the presence of high-frequency spatial harmonics. These harmonics are caused by the interaction between the stator slotting and the rotor barriers. This interaction results in zigzag leakage flux, which occurs when stator flux crosses the air gap to the rotor and then returns to the stator without passing through the rotor flux barriers. This is especially evident near $45^{\circ}$ where the flux density repeatedly reverses polarity. The waveform has a fundamental component with a peak value of $0.51 \mathrm{~T}$.

The short-circuit air-gap flux density waveform [Fig. 6(c)] is ideally the sum of the air-gap flux density waveforms from the open-circuit and reluctance rotor cases. The fundamental components of the rotor flux and $d$-axis stator flux nearly cancel one another out leaving a residue of high-amplitude harmonic components. These spatial harmonic components appear to be due to both the distorted $d$-axis stator flux distribution and the rectangular magnet flux distribution, and could result in highharmonic iron losses.
If superposition could be applied, then the fundamental component in the short-circuit case would be the difference between the fundamental components of the open-circuit and reluctance rotor cases. Its magnitude would be $0.66 \mathrm{~T}-0.51 \mathrm{~T}=0.15 \mathrm{~T}$. This is close to the actual fundamental component of $0.19 \mathrm{~T}$ and the difference is likely to be due to effects of nonlinearities such as saturation reducing the fundamental rotor magnet flux under open-circuit conditions.

The value of rated current used $(9.4 \mathrm{~A})$ was chosen to reduce the fundamental component of the stator voltage to zero at the stator terminals. The rated current is equal to the forced-running short-circuit current at high speeds. It does not correspond to zero air-gap spatial fundamental flux because of the finite leakage inductance (due to slot and end-winding leakage) of the machine.

Iron losses are associated with time variations in the flux density rather than spatial variations, therefore, in the next section, the time-varying machine flux distribution is investigated to see whether these high-harmonic spatial flux components results in high-harmonic time-varying flux components.

\section{B. Stator Tooth Flux Density Variation With Time}

The majority of iron losses in synchronous machines normally occur in the stator, as ideally the rotor does not see a changing magnetic field. To better understand the stator iron losses, the magnetic flux variation in the stator teeth was examined using both measurements and FEA.

The variation of the stator tooth flux density under opencircuit and short-circuit conditions was measured using a search coil wound around a stator tooth. To obtain the stator tooth flux associated with the air-gap flux, it is important to insert the search coil as close as possible to the air gap. The location of the search coil is illustrated in Fig. 7. The search coil covers a single stator tooth and consists of five turns of fine wire. The stator tooth flux waveform was obtained by integrating the search coil induced voltage. This was performed using a resistor-capacitor first-order low-pass filter whose cutoff frequency of $5 \mathrm{~Hz}$ is much lower than the $50 \mathrm{~Hz}$ fundamental frequency. The flux in the tooth $\phi(t)=\nu(t) \mathrm{RC} / N$, where $\nu(t)$ is the output of the integrator, $\mathrm{RC}=0.033 \mathrm{~s}$ is the time constant of the low-pass filter, and $N=5$ is the number of turns in the search coil.

The stator tooth flux waveform was calculated using the finite-element package by rotating the rotor in $1^{\circ}$ (mechanical) steps. Fig. 8 shows flux plots for the open and short-circuit cases using the rotating finite-element model for a particular rotor position. The flux in the stator teeth was calculated, and the search coil induced voltage determined as the rate of change of flux linkage with time.

Fig. 9 shows shaded flux density plots for a particular rotor position for the open and short-circuit cases. Note that this rotor position is different to that shown in Fig. 8. The lighter shading corresponds to regions of highest flux density. Fig. 9(a) shows that under open-circuit conditions, the highest flux densities occurs in the stator teeth, in parts of the stator back iron and in some of the rotor barriers. Fig. 9(b) shows that under shortcircuit conditions, the flux in the machine is much lower in general, however there are still high flux densities around the 

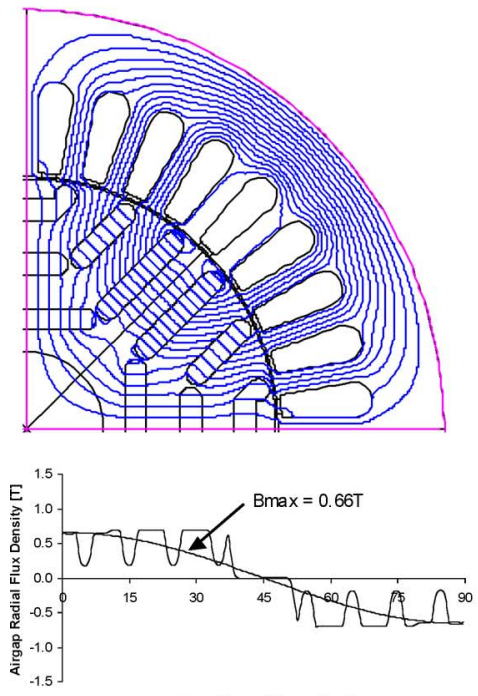

(a)
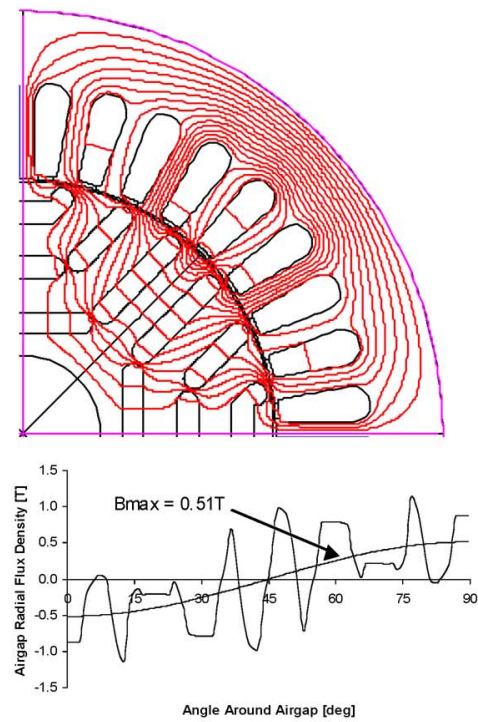

(b)
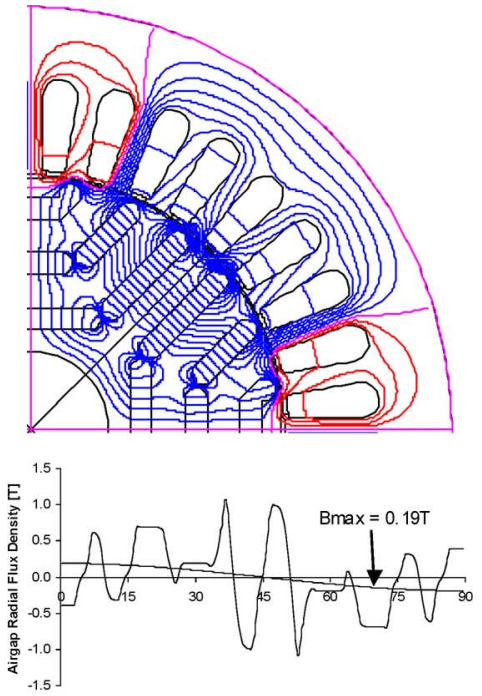

(c)

Fig. 6. Finite-element flux plot and air-gap radial flux distribution showing fundamental component. (a) Rotor magnets only. (b) Reluctance rotor with $d$-axis current. (c) Both magnets and currents.

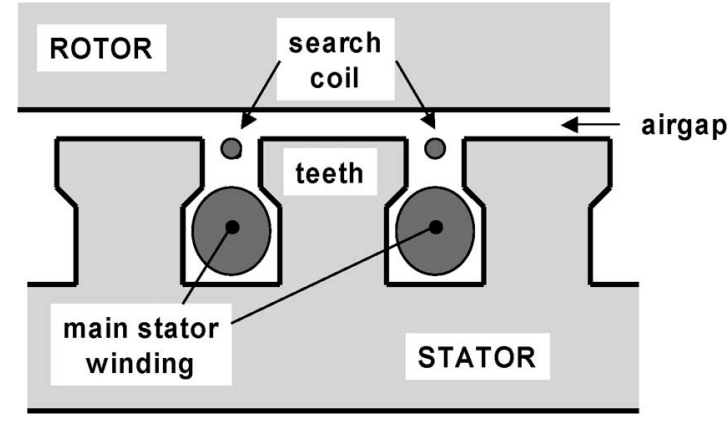

Fig. 7. Diagram showing the location of the search coil [8].

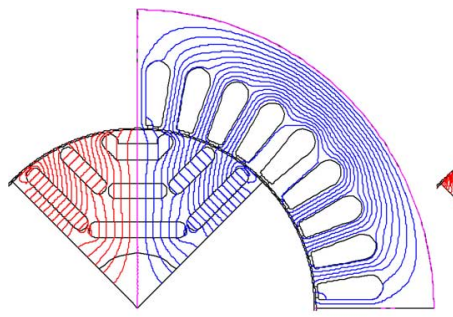

(a)

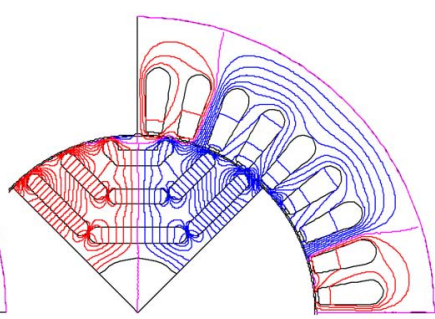

(b)
Fig. 8. Rotating FEA models used in simulations. (a) Open-circuit case. (b) Short-circuit case.

immediate vicinity of the air gap and in two of the stator teeth in each pole. The high flux densities in the saturated rotor bridges are also evident.

Figs. 10 and 11 show a comparison of the measured and the calculated search coil voltage and tooth flux for the opencircuit and short-circuit cases, respectively, at $1500 \mathrm{r} / \mathrm{min}$ $(50 \mathrm{~Hz})$. In the open-circuit case in Fig. 10, the measured flux waveform is roughly rectangular but shows a significant asymmetry. This is likely to be due to either an asymmetrical magnetization/placement of the rotor magnets, or local demagnetization due to the field-weakening operation. Avoiding de-

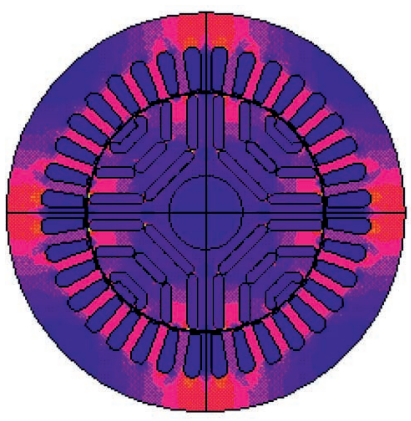

(a)

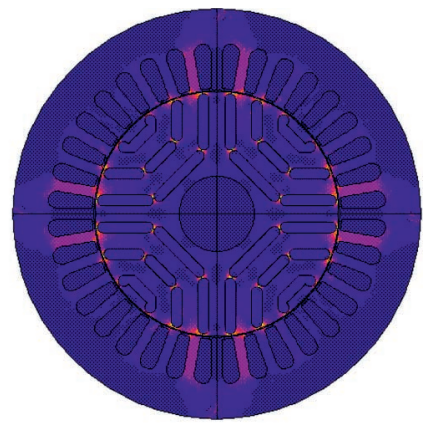

(b)
Fig. 9. Flux density distribution of the concept demonstrator in the (a) opencircuit and (b) short-circuit (field-weakening) conditions.
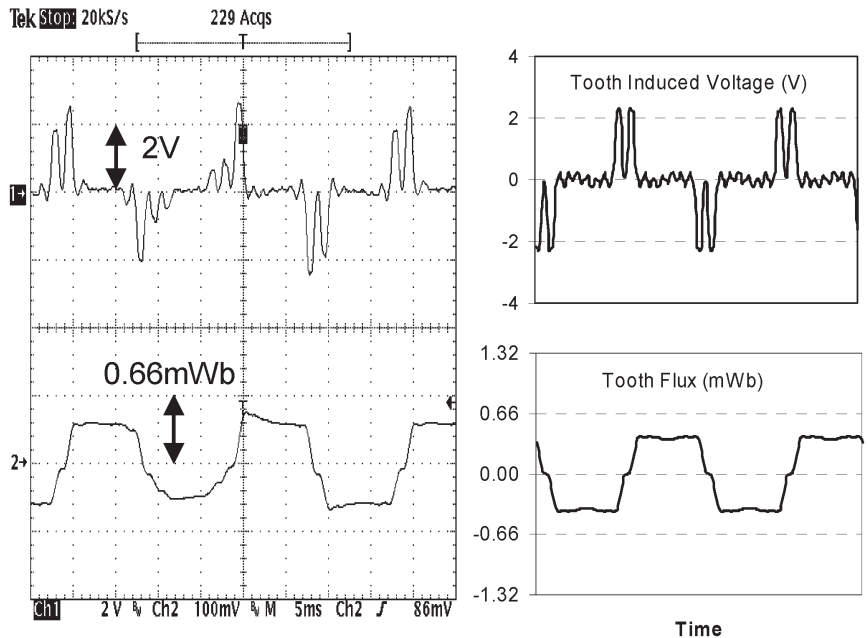

Fig. 10. Open-circuit case. Search coil induced voltage (upper graphs) and corresponding stator tooth flux waveform (lower graphs) at $1500 \mathrm{r} / \mathrm{min}$. (Left) Measured and (right) calculated from FEA.

magnetization is important in this alternator, which is operated near the short-circuit condition, and it is planned to investigate 

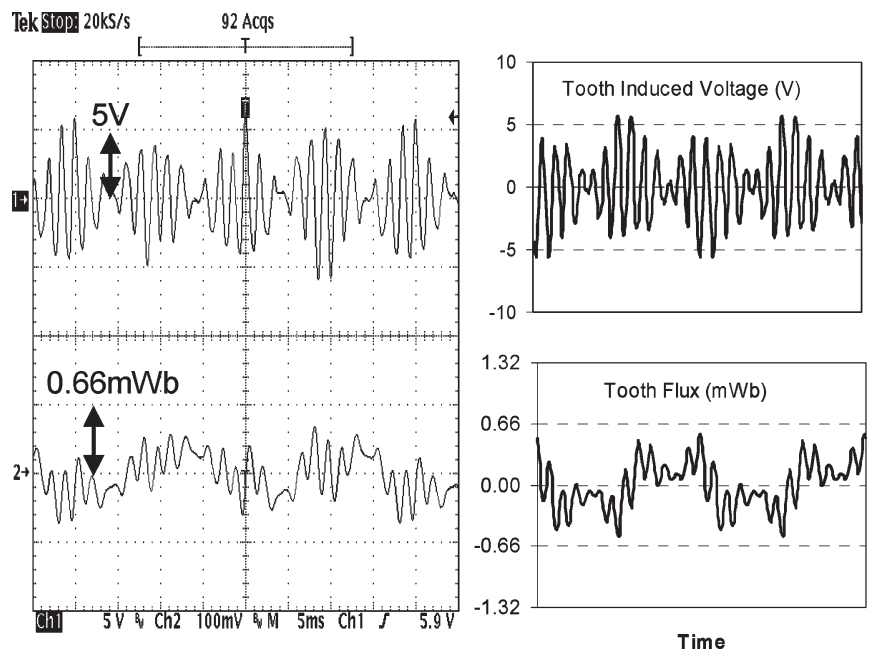

Fig. 11. Short-circuit case. Search coil induced voltage (upper graphs) and corresponding stator tooth flux waveform (lower graphs) at $1500 \mathrm{r} / \mathrm{min}$. (Left) Measured and (right) calculated from FEA.

this issue further in the future. Apart from this assymmetry, the magnitudes and shapes of the calculated waveforms match well with the measured results.

In the short-circuit case in Fig. 11, ideally the tooth flux should be zero. In practice, the fundamental component of the tooth flux is reduced significantly compared to the opencircuit case, however there are now large harmonic components present. These components are particularly apparent in the induced voltage waveform. The high amplitude of these harmonic flux components would result in high iron losses in the stator teeth. The finite-element results again show a good correspondence with the measured results both in magnitude and waveform shape.

The calculated tooth flux $\phi$ waveforms in Figs. 10 and 11 were scaled by the area of the tooth $A$ to obtain the tooth flux density $B=\phi / A$ waveforms in Fig. 12 for the open- and shortcircuit cases. These waveforms were used in calculating the iron loss in the teeth.

\section{Stator Tooth Iron Loss Calculation}

The standard analytical formula for the iron loss $P_{\mathrm{fe}}$ for a sinusoidally varying flux density of peak value $B_{\mathrm{pk}}$ and frequency $f$ when skin effect can be neglected is [9], [10]

$$
P_{\mathrm{fe}}=C_{\mathrm{h}} f B_{\mathrm{pk}}^{a+b B_{\mathrm{pk}}}+C_{\mathrm{e}} f^{2} B_{\mathrm{pk}}^{2}
$$

where $C_{\mathrm{h}}$ is the hysteresis loss coefficient, $C_{\mathrm{e}}$ is the eddycurrent loss coefficient, and $a$ and $b$ are constants. These four parameters are dependent on the type and thickness of the laminated magnetic material.

For nonsinusoidal waveforms, the eddy-current term in (1) can be modified to give the following expression [10]:

$$
P_{\mathrm{fe}}=C_{\mathrm{h}} f B_{\mathrm{pk}}^{a+b B_{\mathrm{pk}}}+C_{e 1}\left[\frac{d B}{d t}\right]^{2}
$$
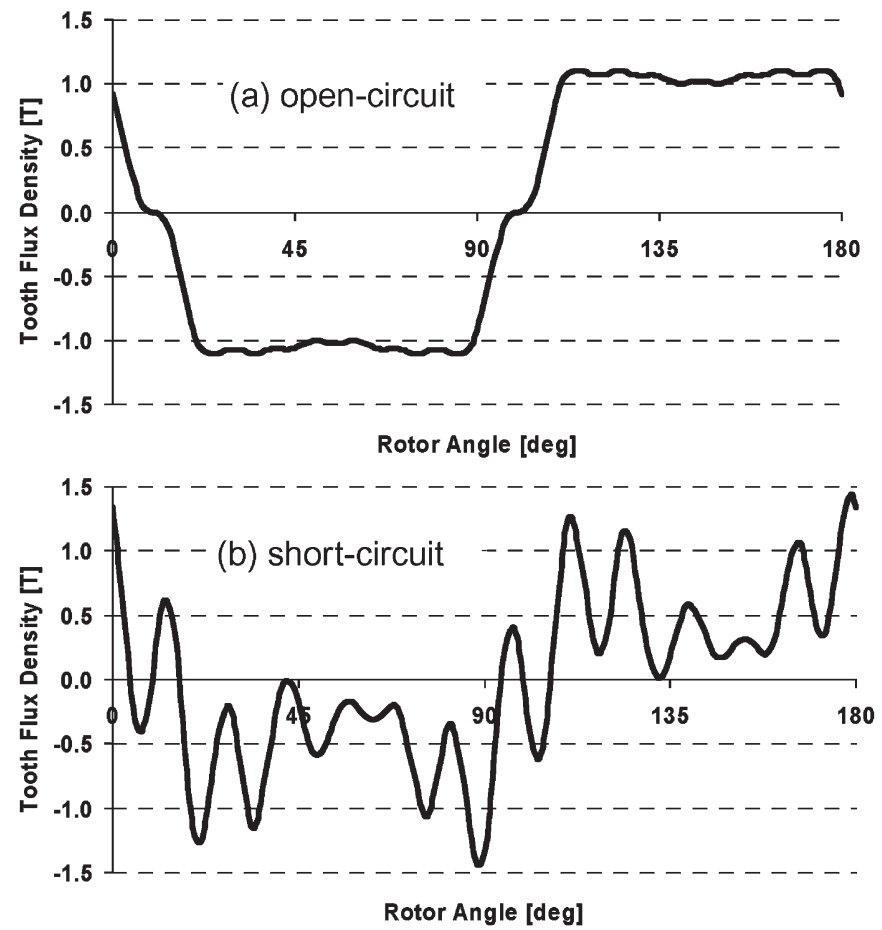

Fig. 12. Calculated open-circuit and short-circuit tooth flux density versus time (rotor angle).

where $C_{e 1}=C_{\mathrm{e}} /\left(2 \pi^{2}\right)$ is the new eddy-current coefficient, and $[d B / d t]$ is the rms value of the rate of change of flux density over one cycle of the fundamental frequency.

The iron loss coefficients for the stator lamination material (0.5-mm-thick Polycor made by European Electrical Steels) are as follows: $C_{\mathrm{h}}=0.02094, C_{e 1}=1.296 \times 10^{-5}, a=1.321$ and $b=0.462$ which when used in (2), yields an iron loss in watts per kilogram.

The iron loss in the stator teeth was calculated using the tooth flux density waveforms in Fig. 12 and (2) for both the open and short-circuit cases. Fig. 13 presents a comparison of the calculated iron loss in the stator teeth with the measured total iron and mechanical losses (as shown earlier in Fig. 4) for the concept demonstrator machine.

It was found that the eddy-current loss was dominant in this machine at higher speeds. At $6000 \mathrm{r} / \mathrm{min}(200 \mathrm{~Hz})$, the hysteresis loss was about $10 \%$ of the total loss under opencircuit conditions and only about $2 \%$ of the total loss under short-circuit conditions.

Fig. 13 shows that in the open-circuit condition, the measured iron and mechanical losses, which include iron losses for the entire machine, are nearly four times larger than the calculated iron losses for the stator teeth alone. This is not surprising given that Fig. 9(a) showed that the stator yoke has high flux densities under open-circuit conditions and that the stator yoke volume is significantly larger than the stator tooth volume. Clearly, the approximation of only considering the iron losses in the stator teeth is not valid in the open-circuit condition. The stator yoke also tends to experience rotational components of flux density [6], [7] which can increase the iron loss beyond what would be predicted using (2). 

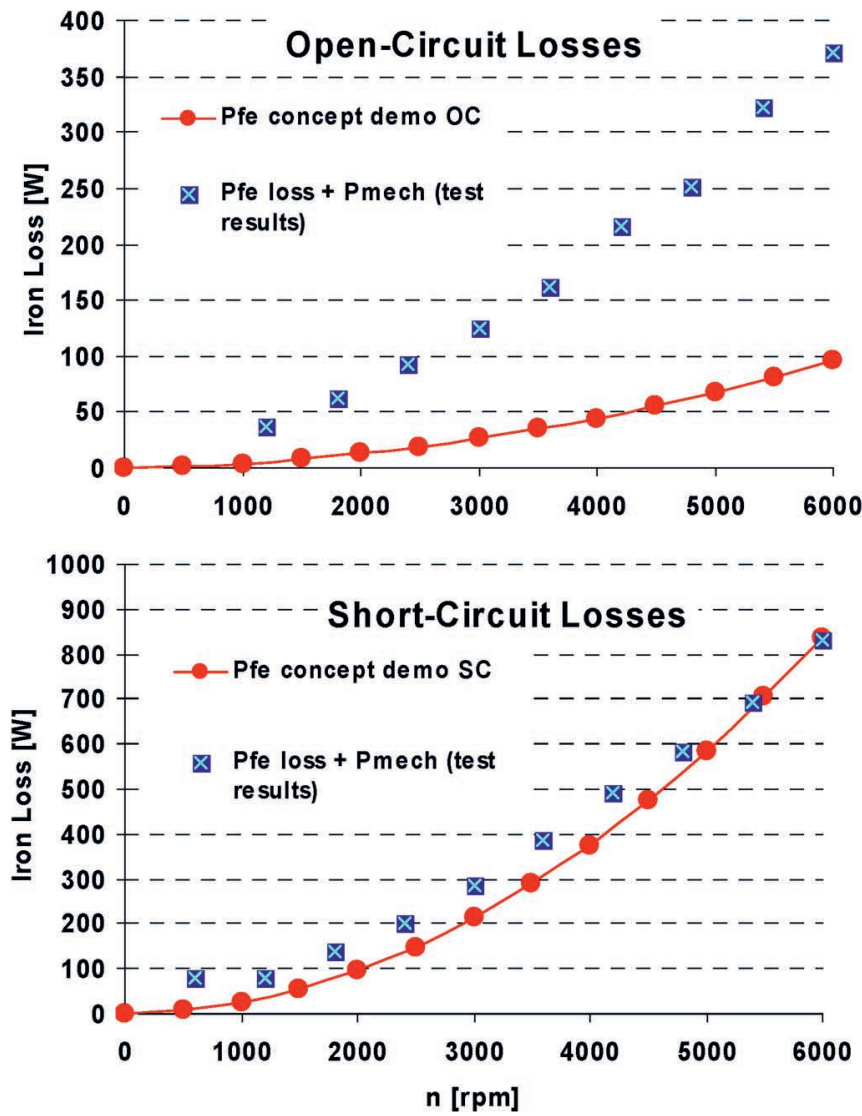

Fig. 13. Comparison of measured iron and mechanical loss (squares) and calculated finite-element stator tooth losses (lines) versus speed for the concept demonstrator.

In the short-circuit condition, the calculated stator tooth iron losses are much closer to the total measured iron and mechanical losses. This can be understood from Fig. 9(b), which showed that under this condition, the largest region with the highest flux density is the stator teeth.

\section{Harmonic Eddy-Current Loss Analysis}

The iron losses in the previous section were calculated using (2) which used the $d B / d t$ relationship for determining the eddy-current losses. An alternative method for calculating iron loss is to perform a Fourier series analysis of the stator tooth flux density waveforms shown in Fig. 12 to obtain the amplitude of each flux density harmonic component. Equation (1) can then be used to calculate the iron losses for each harmonic. This has the advantage of showing the relative contributions of the different frequency components to the iron loss.

The frequency spectrum of the tooth flux density and the eddy-current loss for each harmonic at $6000 \mathrm{r} / \mathrm{min}(200 \mathrm{~Hz})$, are shown in Figs. 14 and 15 for the open-circuit and short-circuit cases, respectively. Only the eddy-current loss is considered as the earlier analysis showed that this is much larger than the hysteresis loss at higher speeds. Note that only odd harmonics are present due to the symmetry of the waveforms.

Fig. 14 shows that under open-circuit conditions the tooth flux density waveform has a predominant fundamental com-
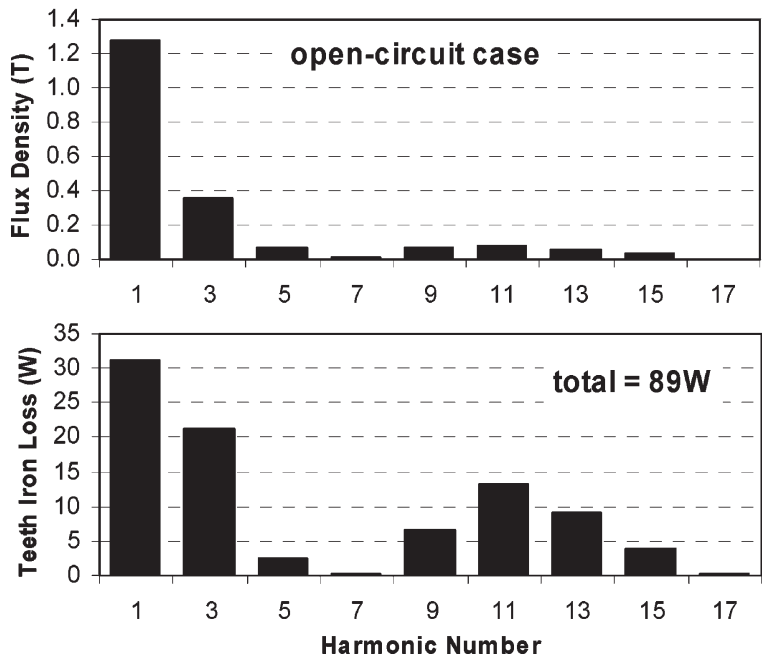

Fig. 14. Open-circuit case. (Upper) Harmonic components of the calculated tooth flux density and (lower) the teeth eddy-current iron loss at $6000 \mathrm{r} / \mathrm{min}$.
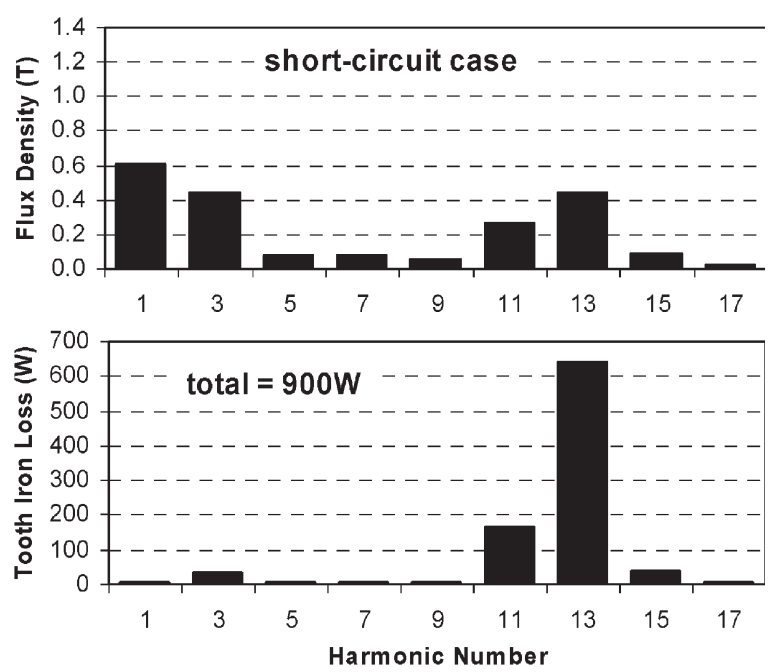

Fig. 15. Short-circuit case. (Upper) Harmonic components of the calculated tooth flux density and (lower) the teeth eddy-current iron loss at $6000 \mathrm{r} / \mathrm{min}$.

ponent while the other harmonics are relatively small in amplitude. From (1), the eddy-current iron loss is proportional to both flux density squared and frequency squared. Thus, low-amplitude higher harmonic components can still produce significant iron losses due to their high frequency. This can be seen in Fig. 14 where though the fundamental iron loss is the largest component, it only makes up one third of the total eddycurrent losses and that the third, ninth, eleventh, thirteenth, and fifteenth harmonic iron loss components are significant. The total calculated eddy-current loss of $89 \mathrm{~W}$ using harmonic analysis is comparable to the calculated eddy-current iron loss of $86 \mathrm{~W}$ using the $d B / d t$ formula in (2).

Fig. 15 shows under short-circuit conditions, that the fundamental component of the tooth flux density is halved, while the higher harmonic components increase in amplitude. In particular, the thirteenth harmonic becomes almost comparable in magnitude to the fundamental component. As the eddy-current loss is proportional to frequency squared, this results in an 

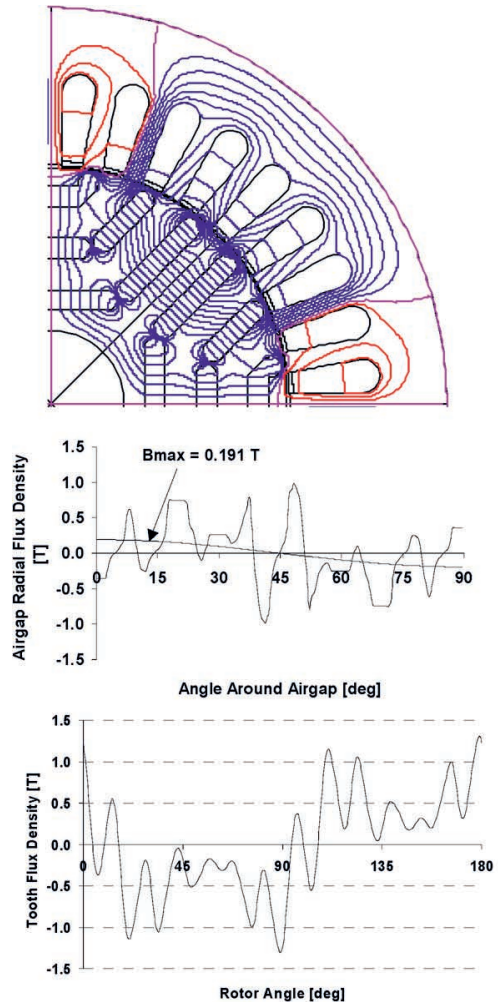

(a)
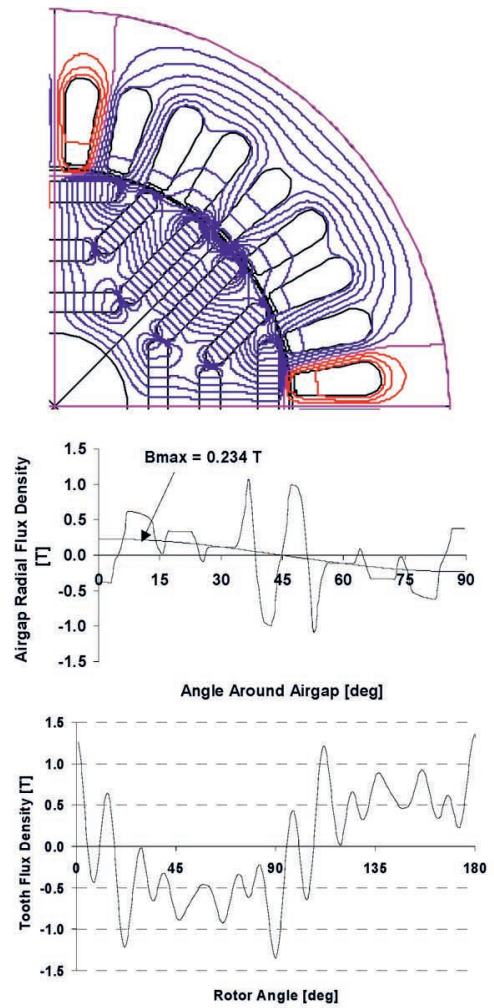

(b)
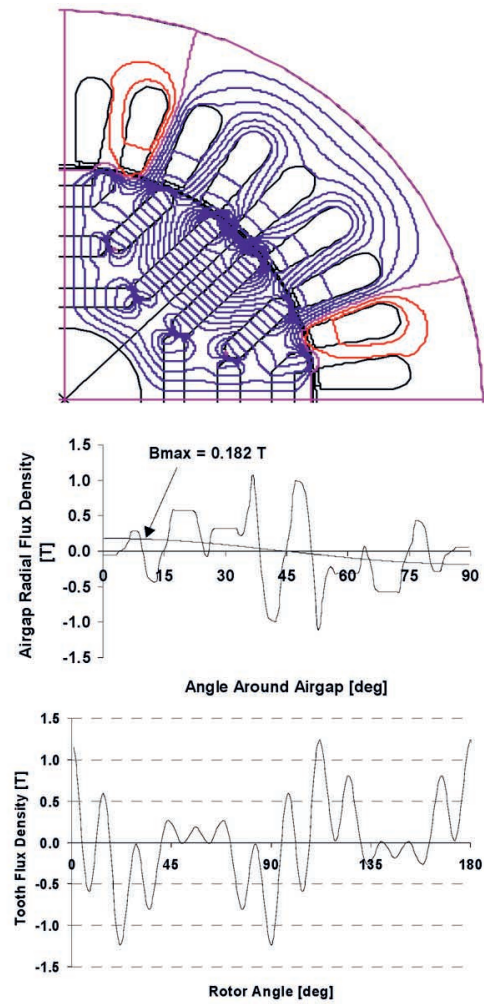

(c)

Fig. 16. (Top) FEA flux plot, (middle) air-gap radial flux distribution with fundamental component, and (bottom) tooth flux density as a function of time under short-circuit conditions. (a) Flat tooth stator. (b) New rotor design. (c) Ideal stator winding.

extremely large iron loss due to this harmonic. It is responsible for nearly two thirds of the total eddy-current loss. Again, the total calculated eddy-current loss of $900 \mathrm{~W}$ using harmonic analysis is comparable with the calculated eddy-current iron loss of $820 \mathrm{~W}$ using the $d B / d t$ formula in (2).

\section{Investigation of Machine Design Changes}

The analysis in the previous section has shown that the reason for the high iron losses in the concept demonstrator machine during field weakening is the presence of high-frequency harmonic flux components, particularly in the stator teeth. It was shown that under field-weakening conditions the iron loss in the machine at higher speeds could be reasonably accurately estimated from the stator tooth flux density waveform. The eddycurrent loss was found to be much larger than the hysteresis loss due to the high frequencies considered.

In this section, the effect of three changes to the concept demonstrator design on its field-weakening iron losses will be investigated with the aid of FEA. The three modified designs are illustrated in Fig. 16. From left to right, they are as follows.

1) Flat stator teeth: The stator teeth were changed to be flatsided, that is, the stator slot openings were widened fully to an "open slot" configuration in an attempt to reduce the zigzag leakage flux.

2) New rotor design: The shape of the smallest rotor barrier was modified to try to improve the rotor flux distribution.

3) Ideal stator windings: The existing design used a threephase single-layer stator winding. In an attempt to im-

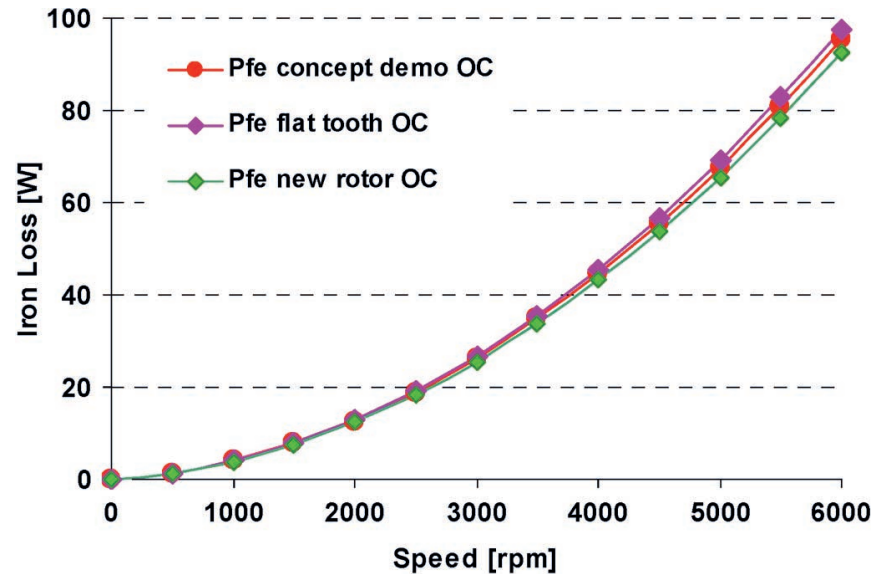

Fig. 17. Open-circuit case. Comparison of calculated stator tooth iron loss between two new designs with the calculated concept demonstrator result.

prove the stator $d$-axis flux distribution, the effect of using a nine-phase single-layer winding was tested. In this winding, the phase angle changes $20^{\circ}$ between every slot.

The aim was to investigate how each change affected the total iron loss under both open-circuit and short-circuit conditions.

\section{A. Iron Loss Comparison for the Open-Circuit Case}

Fig. 17 and Table I present a comparison of the calculated iron loss between the new designs and the concept demonstrator under open-circuit conditions. There are only slight differences 
TABLE I

Comparison of the EFFECT OF MACHINE Design Changes on the CALCUlated IRON LOSSES AND Fundamental AIR-GAP COMPONENTS

\begin{tabular}{|c|c|c|c|c|c|}
\hline Parameter & Case & $\begin{array}{c}\text { Concept } \\
\text { Demo }\end{array}$ & $\begin{array}{l}\text { Flat } \\
\text { Teeth }\end{array}$ & $\begin{array}{l}\text { New } \\
\text { Rotor }\end{array}$ & $\begin{array}{c}\text { Ideal } \\
\text { Stator } \\
\text { Winding } \\
\end{array}$ \\
\hline \multirow{2}{*}{$\begin{array}{l}\text { Open-circuit } \\
\text { loss at } 6 \\
\text { krpm }\end{array}$} & $\begin{array}{l}\text { Measured } \\
\text { (iron+windage) }\end{array}$ & $371 \mathrm{~W}$ & - & - & - \\
\hline & $\begin{array}{l}\text { Calculated } \\
\text { (teeth only) }\end{array}$ & $95.5 \mathrm{~W}$ & $97.6 \mathrm{~W}$ & $92.6 \mathrm{~W}$ & $\begin{array}{c}\text { same as } \\
\text { concept } \\
\text { demo }\end{array}$ \\
\hline \multirow{2}{*}{$\begin{array}{l}\text { Short-circuit } \\
\text { loss at } 6 \\
\text { krpm }\end{array}$} & \begin{tabular}{|l|}
$\begin{array}{l}\text { Measured } \\
\text { (iron+windage) }\end{array}$ \\
\end{tabular} & $834 \mathrm{~W}$ & - & - & - \\
\hline & $\begin{array}{l}\text { Calculated } \\
\text { (teeth only) }\end{array}$ & $837 \mathrm{~W}$ & $682 \mathrm{~W}$ & $735 \mathrm{~W}$ & $865 \mathrm{~W}$ \\
\hline \multirow{3}{*}{$\begin{array}{l}\text { Calculated } \\
\text { peak } \\
\text { fundamental } \\
\text { air gap } \\
\text { magnetic } \\
\text { flux density }\end{array}$} & $\begin{array}{l}\text { open-circuit } \\
\text { case }\end{array}$ & $0.667 \mathrm{~T}$ & $0.646 \mathrm{~T}$ & $0.662 \mathrm{~T}$ & $\begin{array}{l}\text { same as } \\
\text { concept } \\
\text { demo }\end{array}$ \\
\hline & $\begin{array}{l}\text { reluctance case } \\
\text { d-axis stator } \\
\text { flux only } \\
\end{array}$ & $0.512 \mathrm{~T}$ & $0.502 \mathrm{~T}$ & $0.495 \mathrm{~T}$ & $0.525 \mathrm{~T}$ \\
\hline & $\begin{array}{l}\text { short-circuit } \\
\text { case }\end{array}$ & $0.191 \mathrm{~T}$ & $0.191 \mathrm{~T}$ & $0.234 \mathrm{~T}$ & $0.182 \mathrm{~T}$ \\
\hline
\end{tabular}

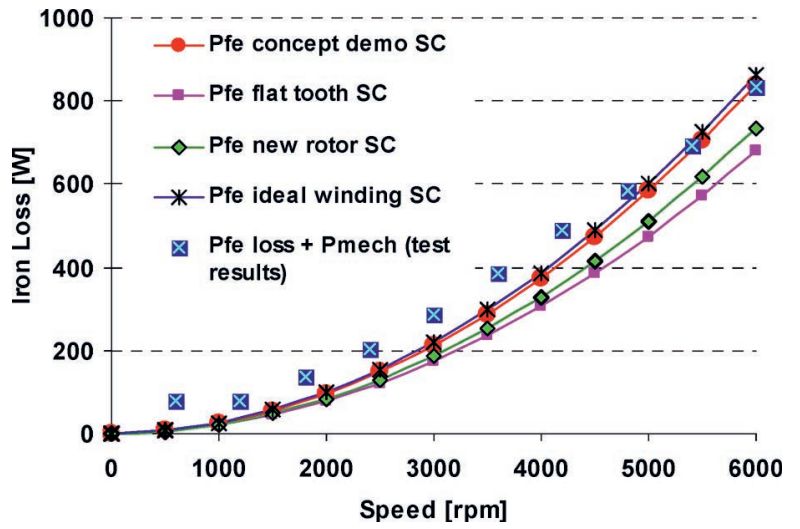

Fig. 18. Short-circuit case. Comparison of calculated stator tooth iron loss between the three new designs with the calculated and measured concept demonstrator results.

between the open-circuit iron losses. Compared to the concept demonstrator, the flat stator tooth case shows slightly higher iron loss and the new rotor design shows slightly lower iron loss. The ideal stator winding design has identical losses to the concept demonstrator under open-circuit conditions and is not shown.

\section{B. Iron Loss Comparison for the Short-Circuit Case}

Fig. 16 showed the flux plots, air-gap radial flux distributions, and the tooth flux density versus time waveforms for the three designs under short-circuit conditions. Fig. 18 and Table I present a comparison of the calculated iron loss between the three different designs and the concept demonstrator and also shows the fundamental component of the flux density under open-circuit, reluctance, and short-circuit conditions.

The calculated short-circuit stator teeth iron loss results for the modified designs show that compared to the original design, the iron loss increases by $3.3 \%$ for the ideal stator winding, reduces by $12.4 \%$ for the new rotor design and reduces by $18.6 \%$ with flat teeth. The main difference between the flux distributions in the three cases is that the flux appears to spread

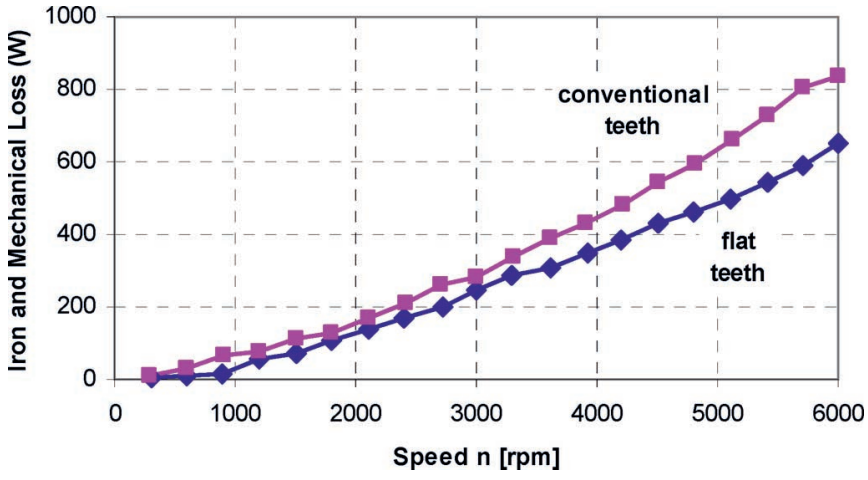

Fig. 19. Comparison of measured short-circuit iron and mechanical losses with conventional and flat teeth.

slightly more evenly over the stator teeth with the flat tooth stator. This may be due to reduced leakage flux.

These calculations show that a reduction of iron loss is possible by using flat stator teeth and changing the rotor barrier shape.

As was found with the concept demonstrator design, under field-weakening conditions the air-gap radial flux density distribution of all three designs show large peaks in the vicinity of $45^{\circ}$. These peaks may make a significant contribution to the iron losses. The flux density peaks can be reduced in amplitude by changing the number of stator slots and/or increasing the number of rotor barriers. This should result in a smoother flux distribution in the machine and, hence, lower iron loss.

\section{Skin Effects at High Speed}

An alternator speed of $6000 \mathrm{r} / \mathrm{min}$ corresponds to a fundamental frequency of $200 \mathrm{~Hz}$. The large thirteenth harmonic component observed under short-circuit conditions corresponds to a frequency of $2.6 \mathrm{kHz}$. At the maximum design speed of $18000 \mathrm{r} / \mathrm{min}$, this thirteenth harmonic will have a frequency of $7.8 \mathrm{kHz}$. The above analysis has neglected skin effect, but at these high frequencies, the skin effect will have a significant influence on the flux density waveforms and the resulting iron losses [9].

\section{Summary of EXPERIMENTAL VALIDATION}

The concept of reducing iron losses by using flat teeth in the concept demonstrator machine was experimentally verified. This was done by measuring the machine performance with conventional stator teeth, and then performing a careful machining operation (with the stator windings still in place) to open up all the slot openings to produce flat teeth. Fig. 19 shows a comparison of the measured short-circuit iron loss before and after the machining operation showing a significant reduction as predicted in Section III. This measured reduction is about $21 \%$ (averaged over the speeds from 3000 to $6000 \mathrm{r} / \mathrm{min}$ ) and compares well with the finite-element prediction of $19 \%$.

Using flat teeth reduced the measured induced back EMF voltage $(3.6 \%)$ due to the increased Carter's coefficient, and also reduced the $d$-axis inductance $(6.4 \%)$ due to the reduced slot leakage. The net effect is a slight increase in the measured 
short-circuit current $(3.0 \%)$. The power output versus speed curve and efficiency both improved slightly at high speeds but the improvement due to the reduced iron losses and higher short-circuit current was partly offset by higher copper losses under this condition.

Space limitations prevent a more complete analysis of the experimental results but these will be discussed more fully in a subsequent paper.

\section{CONClusion}

This paper has investigated means for iron loss reduction in an interior PM automotive alternator operating over a wide field-weakening range. The main findings of this paper are as follows.

1) The measured iron losses in the interior PM machine under field-weakening operation were comparable to the iron losses under short-circuit conditions, and were approximately twice the open-circuit iron losses.

2) The high iron loss in the machine during field-weakening is due to large amplitude, higher harmonic flux components caused by the interaction of the high PM rotor flux and the $d$-axis stator flux distribution.

3) The calculated stator tooth flux density waveforms using FEA have a good correspondence with the measured results under both open-circuit and short-circuit conditions.

4) Under short-circuit conditions, the calculated iron loss in the stator teeth was found to be close to the measured iron loss in the machine.

5) The analysis showed that eddy-current loss was dominant in this machine at higher speeds, and that under shortcircuit conditions the majority of the iron loss was due to a large thirteenth harmonic flux density component.

6) The calculated effect of three machine design changes on the short-circuit iron loss were examined, of these increasing the slot opening using flat teeth offered the greatest reduction $(19 \%)$.

7) An experimental verification of the use of flat stator teeth was performed and the measured iron loss reduction (21\%) at high speed was comparable to the calculated effect, and the output power was shown to improve slightly.

Future work includes further optimization of the machine design to reduce iron losses and further experimental validation of the results.

\section{ACKNOWLEDGMENT}

The authors would like to thank C. Z. Liaw, D. M. Whaley, and the staff of the School of Electrical and Electronic Engineering's mechanical workshop for the technical support during the experimental testing, and T. J. E. Miller for providing the Polycor lamination data.

\section{REFERENCES}

[1] E. C. Lovelace, "Optimization of a magnetically saturable interior permanent-magnet synchronous machine drive," Ph.D. dissertation, Dept. Elect. Eng. Comput. Sci., Massachusetts Inst. Technol., Cambridge, MA, 2000 .
[2] W. L. Soong and N. Ertugrul, "Inverterless high-power interior permanent-magnet automotive alternator," IEEE Trans. Ind. Appl., vol. 40, no. 4, pp. 1083-1091, Jul./Aug. 2004.

[3] C. Z. Liaw, D. M. Whaley, W. L. Soong, and N. Ertugrul, "Implementation of inverterless control of interior permanent magnet alternators," in Conf. Rec. IEEE-IAS Annu. Meeting, 2004, pp. 276-283.

[4] K. J. Tseng and S. B. Wee, "Analysis of flux distribution and core losses in interior permanent magnet motor," IEEE Trans. Energy Convers., vol. 14, no. 4, pp. 969-975, Dec. 1999.

[5] B. Stumberger, A. Hamler, M. Trlep, and M. Jesenik, "Analysis of interior permanent magnet synchronous motor designed for flux weakening operation," IEEE Trans. Magn., vol. 37, no. 5, pp. 3644-3647, Sep. 2001.

[6] B. Stumberger, A. Hamler, and B. Hribernik, "Analysis of iron loss in interior permanent magnet synchronous motor over a wide-speed range of constant output power operation," IEEE Trans. Magn., vol. 36, no. 41, pp. 1846-1849, Jul. 2000.

[7] R. Schiferl and T. A. Lipo, "Core loss in buried magnet permanent magnet synchronous motors," IEEE Trans. Energy Convers., vol. 4, no. 2, pp. 279-284, Jun. 1989.

[8] V. Životić-Kukolj, W. L. Soong, and N. Ertugrul, "Investigation of iron losses in a high flux interior PM automotive alternator," in Proc. Australas. Univ. Power Eng. Conf., Sep. 2004, CD-ROM.

[9] V. Gourishanker, Electro-Mechanical Energy Conversion. Scranton, PA: International Textbook, 1965.

[10] J. R. Hendershot and T. J. E. Miller, Design and Performance of Brushless Permanent-Magnet Motors. London, U.K.: Oxford Univ. Press, 1994.

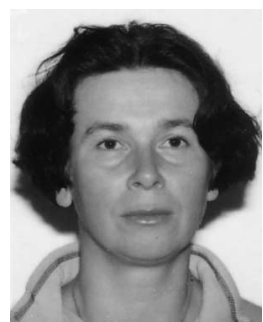

Vlatka Životić-Kukolj was born in Zagreb, Croatia, in 1962. She received the degree in electrical power engineering from the University of Zagreb, Zagreb, Croatia, in 1986, and the M.Eng.Sci. degree from the University of Adelaide, Adelaide, Australia, where she is currently working toward the Ph.D. degree, in 2001.

The first three years of her career were spent with the Rade Končar Research Institute, Zagreb. The next three and a half years of her work were with Dalekovod (an electrical power transmission and distribution company) in Zagreb. She migrated to Adelaide, Australia, in 1993. Her main fields of interest are the design of small electrical machines and electrical power systems.

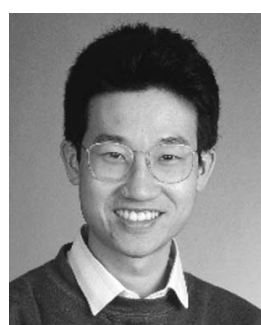

Wen L. Soong (S'89-M'93) was born in Kuala Lumpur, Malaysia. He received the B.Eng. degree from the University of Adelaide, Adelaide, Australia, in 1989, and the Ph.D. degree from the University of Glasgow, Glasgow, U.K., in 1993.

He was an Electrical Engineer for four years with the Power Controls Program at General Electric Corporate Research and Development, Schenectady, NY, before taking up a teaching position in the Electrical and Electronic Engineering Department at the University of Adelaide, in 1998. His present research interests include permanent-magnet (PM) and reluctance machines, renewable energy generation, magnetic levitation, and condition monitoring and diagnostics.

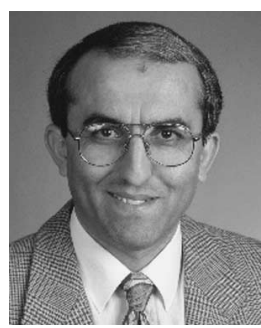

Nesimi Ertugrul (M'95) received the B.Sc. degree in electrical engineering and the M.Sc. degree in electronic and communication engineering, both from Istanbul Technical University, Istanbul, Turkey, in 1985 and 1989, respectively, and the Ph.D. degree from the University of Newcastle upon Tyne, Newcastle upon Tyne, U.K., in 1993.

Since 1994, he has been with Adelaide University, Adelaide, Australia, where he is a Senior Lecturer. His primary research topics include sensorless operation of switched motors, fault-tolerant motor drives, condition monitoring, and electric vehicles. He is the author of LabVIEW for Electric Circuits, Machines, Drives and Laboratories (Prentice-Hall, 2002).

Dr. Ertugrul serves on the Editorial Advisory Board for the International Journal of Engineering Education (IJEE). 